\title{
Idelalisib/Rituximab Regimen
}

National Cancer Institute

\section{Source}

National Cancer Institute. Idelalisib/Rituximab Regimen. NCI Thesaurus. Code C160530.

A regimen consisting of idelalisib and rituximab that may be used in the treatment of chronic lymphocytic leukemia (CLL)/small lymphocytic lymphoma (SLL). 